\title{
Model for zinc oxide varistor
}

\author{
J. D. Santos, E. Longo, and E. R. Leite \\ Departamento de Química Universidade Federal de São Carlos, C.P. 676, 13565-905, São Carlos, \\ SP, Brazil \\ J. A. Varela \\ Universidade Estadual Paulista, Instituto de Química, C.P. 355, 14800-900, Araraquara, SP, Brazil
}

(Received 13 February 1996; accepted 19 December 1997)

Zinc oxide varistors are very complex systems, and the dominant mechanism of voltage barrier formation in these systems has not been well established. Yet the MNDO quantum mechanical theoretical calculation was used in this work to determine the most probable defect type at the surface of a $\mathrm{ZnO}$ cluster. The proposed model represents well the semiconducting nature as well as the defects at the $\mathrm{ZnO}$ bulk and surface. The model also shows that the main adsorption species that provide stability at the $\mathrm{ZnO}$ surface are $\mathrm{O}^{-}, \mathrm{O}_{2}{ }^{-}$, and $\mathrm{O}_{2}$.

\section{INTRODUCTION}

The grain boundary strongly affects the electrical conductivity of polycrystalline solids. ${ }^{1}$ The lack of lattice periodicity due to intrinsic defects causes a superficial rearrangement of localized states at the grain boundaries. Some atomic defects can also be introduced by impurities during processing of powders and segregation at the grain boundaries. All these localized defects lead to a high density of structural defects that can originate a potential barrier associated to a double space charge distribution. These associated phenomena establish variable resistance as a function of the applied electric field to the solid.

Electronic ceramics based on the grain boundary phenomena went through extraordinary advances after studies on the varistor effect of zinc oxide conducted by Matsuoka. ${ }^{2}$ In order to understand the bulk and grain boundary effect on the conductivity of these ceramics, it is necessary to consider both microscopic and physical chemistry analyses.

Two types of point defects are related to the $\mathrm{ZnO}$ crystal: Frenkel and Schottky defects. ${ }^{3}$ The predominant defect in the $\mathrm{ZnO}$ ceramics has not been well established yet. According to Mahan ${ }^{4}$ the predominant defects in $\mathrm{ZnO}$ are of the Schottky type where oxygen vacancies are the dominant intrinsic donors. However Schwing and Hoffmann ${ }^{5}$ proposed that oxygen vacancies are dominant only at high temperatures. These defects can be ionized and behave like electron donors and acceptors.

Interstitial zinc and oxygen vacancies are electron donors and can be single or double ionized and are represented by using Kroeger-Vink notation $a^{6}$ :

$$
\begin{aligned}
\mathrm{Zn}_{i} & \rightarrow \mathrm{Zn}_{i}{ }^{\bullet}+e^{\prime}, \\
\mathrm{Zn}_{i} & \rightarrow \mathrm{Zn}_{i} \cdot e^{\prime}, \\
\mathrm{V}_{\mathrm{O}}^{\mathrm{x}} & \rightarrow \mathrm{V}_{\mathrm{O}}{ }^{\cdot}+e^{\prime}, \\
\mathrm{V}_{\mathrm{O}} & \rightarrow \mathrm{V}_{\mathrm{O}} \cdot+e^{\prime} .
\end{aligned}
$$

Electron acceptors are zinc vacancies that can be single or double ionized:

$$
\begin{aligned}
& \mathrm{V}_{\mathrm{Zn}}{ }^{\mathrm{x}} \rightarrow \mathrm{V}_{\mathrm{Zn}^{\prime}}+\mathrm{h}^{\bullet}, \\
& \mathrm{V}_{\mathrm{Zn}}{ }^{\prime} \rightarrow \mathrm{V}_{\mathrm{Zn}^{\prime \prime}}+\mathrm{h}^{\bullet} .
\end{aligned}
$$

Gupta and Carlson ${ }^{7}$ proposed a model for the voltage barrier in $\mathrm{ZnO}$ varistor in which the negative charge located in the grain boundary is compensated by a positive charge at the depletion layer. In this model the negative charges are $\mathrm{V}_{\mathrm{Zn}}{ }^{\prime}$ and $\mathrm{V}_{\mathrm{Zn}}{ }^{\prime \prime}$ and the positive charges $\mathrm{V}_{\mathrm{O}}{ }^{\bullet}, \mathrm{V}_{\mathrm{O}}{ }^{\bullet}, \mathrm{Zn}_{i}{ }^{\bullet}, \mathrm{Zn}_{i}{ }^{\bullet}$, and $\mathrm{M}_{\mathrm{Zn}}{ }^{\bullet}$, where $\mathrm{M}$ is $\mathrm{Sb}$ or $\mathrm{Bi}$.

The varistor degradation is associated with the decrease of the voltage barrier at the grain boundary which is related to the annihilation of trapped defects. Several mechanisms have been proposed to explain the degradation phenomena of $\mathrm{ZnO}$ varistors, such as electron traps, ion migration, and oxygen loss. ${ }^{8-11}$

The objective of the present study is to determine, by quantum mechanical study, the probable mechanism for voltage barrier formation and for degradation of $\mathrm{ZnO}$ varistors.

\section{MODEL AND QUANTUM MECHANICAL METHOD}

The calculations were performed with the aid of the $\mathrm{MNDO}^{12}$ semiempirical methods included in the MOPAC 5.0 program package. ${ }^{13}$ The standard parameters for the zinc atom optimized by Dewar et al. ${ }^{14,15}$ and Stewart ${ }^{16}$ were used.

The use of cluster models has some advantages in chemical analysis, semiconducting analysis of oxides, and in adsorption processes. Due to the large dimensions of such clusters, a quantum chemical study requires the use of semiempirical methods.

The MNDO method has been previously used to study large silicon clusters (Si)n, with $n>10^{17}$ and 
large zinc oxide clusters $(\mathrm{ZnO}) n$, with $n>11,{ }^{18,19}$ which suggests the possibility of using these semiempirical methods for investigating even larger clusters.

The semiempirical calculations were made using the zinc oxide $(\mathrm{ZnO})_{10}$ cluster. The structural parameters of the $(\mathrm{ZnO})_{10}$ cluster used are shown in Fig. 1. The cluster geometry variables were frozen during all the calculations, whereas the geometry variables corresponding to the absorbed gas molecules were fully optimized. The geometry of various configurations were optimized in order to determine the minimum stationary point corresponding to the specific active site interaction of $\mathrm{O}_{2}, \mathrm{O}_{2}^{-1}, \mathrm{O}_{2}^{-2}, \mathrm{O}^{-}, \mathrm{O}^{-2}$ with the $\mathrm{ZnO}$ surface represented by the cluster model (Fig. 2).

\section{RESULTS AND DISCUSSIONS}

According to Fujitsu et al. ${ }^{20}$ adsorption of oxygen atoms and molecules at the grain boundary of $\mathrm{ZnO}$ leads

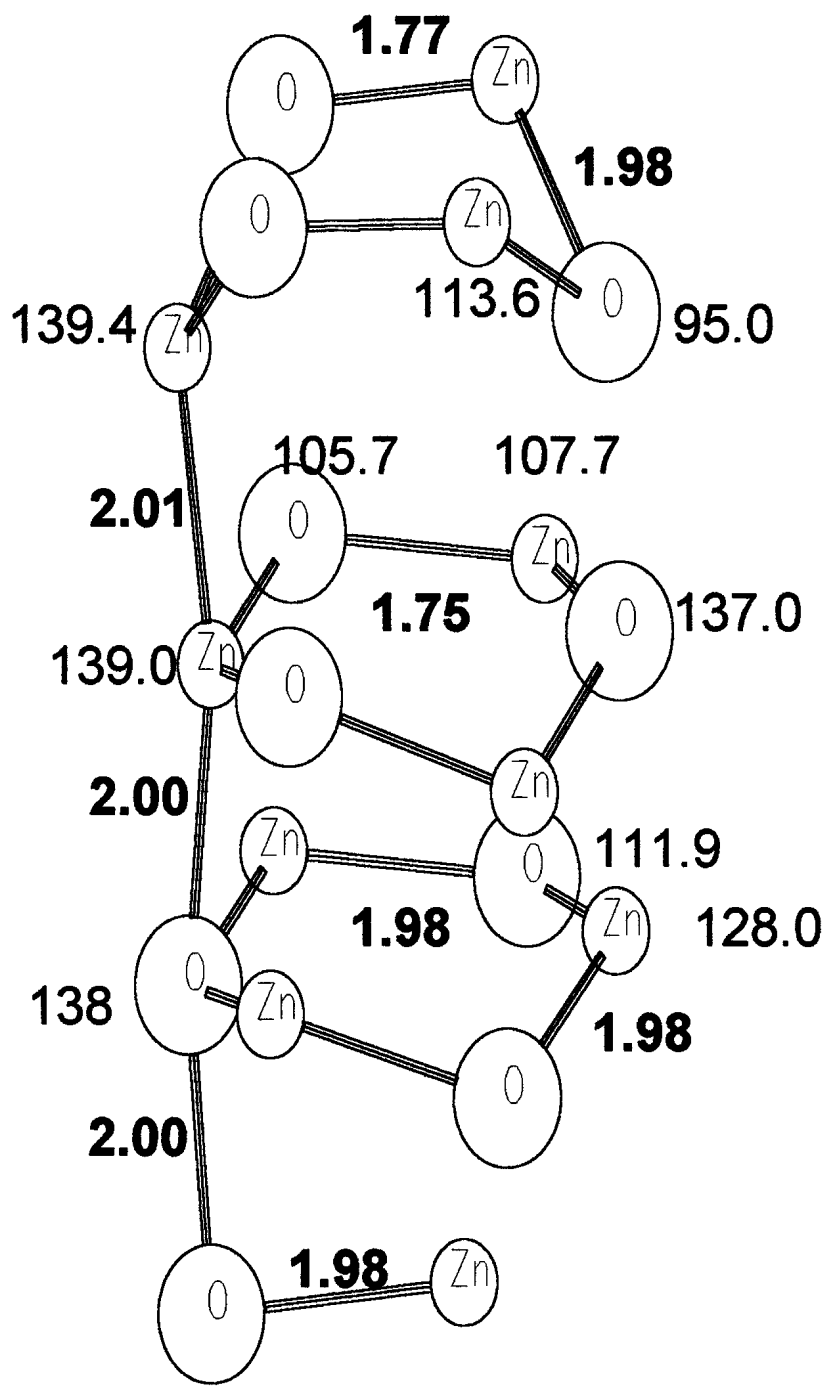

FIG. 1. Structural parameters of the $(\mathrm{ZnO})_{10}$ cluster used in the MNDO calculation.

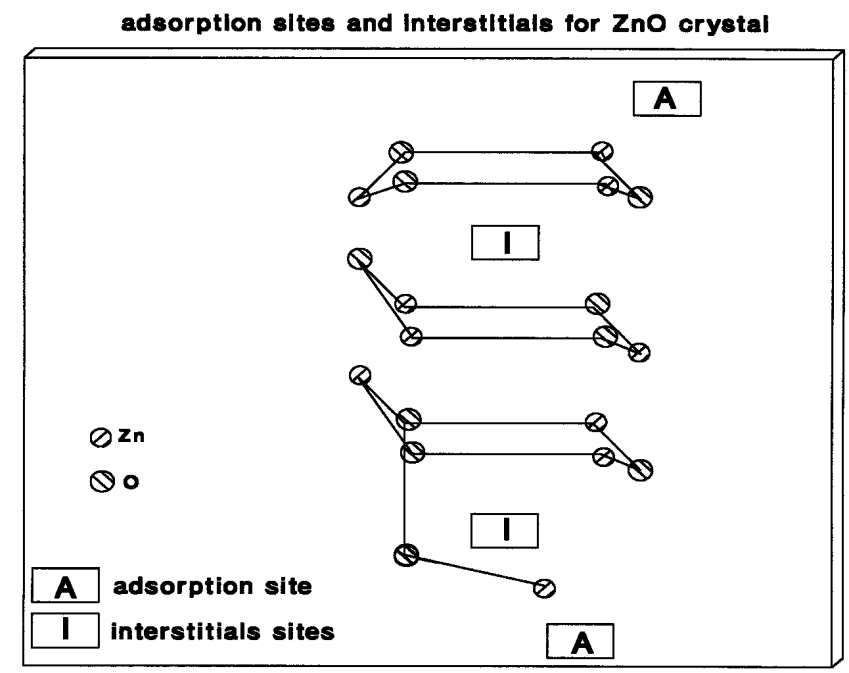

FIG. 2. Schematic representation of the $\mathrm{ZnO}$ cluster showing the adsorption of $\mathrm{O}_{2}, \mathrm{O}_{2}^{-}, \mathrm{O}_{2}^{-2}, \mathrm{O}^{-}$, and $\mathrm{O}^{-2}$ on site $\mathrm{A}$, and interstitial $\mathrm{Zn}_{i}{ }^{\bullet}$ and $\mathrm{Zn}_{i}{ }^{\bullet}$ on site I.

to the formation of the potential barrier and promotes the nonohmic behavior of the $\mathrm{ZnO}$ ceramics. To simulate the oxygen adsorption at the grain surface, a $(\mathrm{ZnO})_{10}$ model was considered for the theoretical calculations. Adsorption of oxygen atoms and molecules as well as the interaction with zinc atoms at the surface was taken into account. Oxygen species used were $\mathrm{O}_{2}, \mathrm{O}_{2}^{-1}, \mathrm{O}_{2}^{-2}$, $\mathrm{O}^{-}$, and $\mathrm{O}^{-2}$.

Figures 3-8 represent the charge distribution of the $(\mathrm{ZnO})_{10}$ and $(\mathrm{ZnO})_{10} \mathrm{Zn}^{+1}$ with the species $\mathrm{O}_{2}, \mathrm{O}_{2}{ }^{-}$, and $\mathrm{O}^{-}$at the $\mathrm{ZnO}$ surface. It is observed that the interaction of oxygen atoms and molecules at the $\mathrm{ZnO}$ surface increases the negative charge density. As a consequence there is a transfer of negative charge from the oxygen atom or molecule to the cluster surface. This result shows

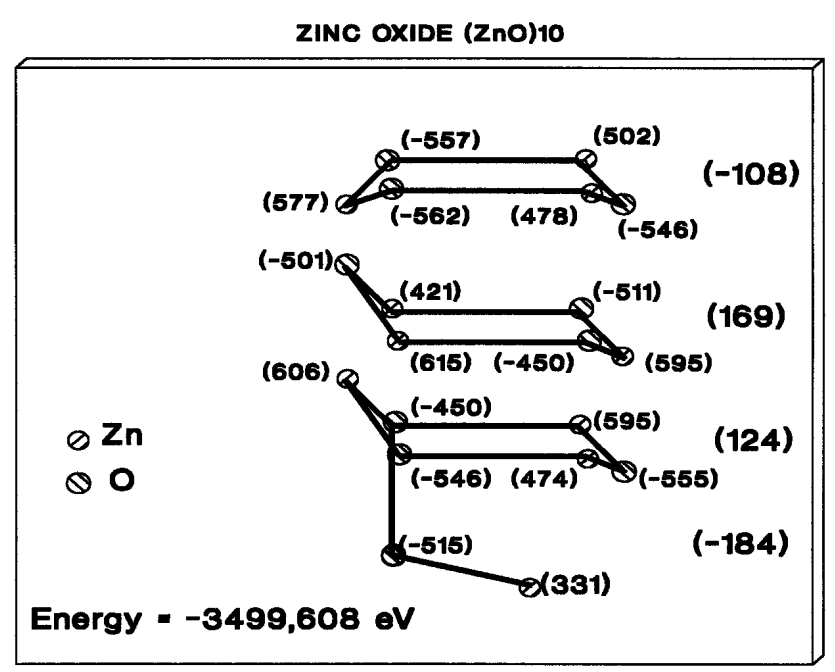

FIG. 3. Charge distribution of the $(\mathrm{ZnO})_{10}$ cluster showing negative charge at the surface and positive charge in the bulk. The numbers in parentheses are the charge value in milielectron. 


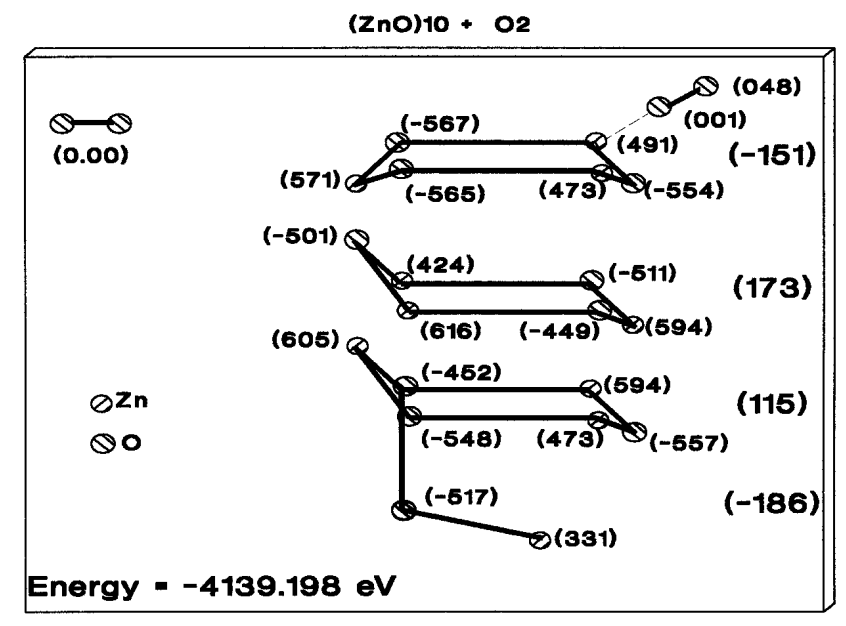

FIG. 4. Charge distribution of the $(\mathrm{ZnO})_{10} \cdot \mathrm{O}_{2}$ cluster showing that the adsorbed oxygen leads to a negative charge at the surface and positive charge in the bulk. The negative charge distribution of this system is higher than that of the $(\mathrm{ZnO})_{10}$ system. The numbers in parentheses are the charge value in milielectron.

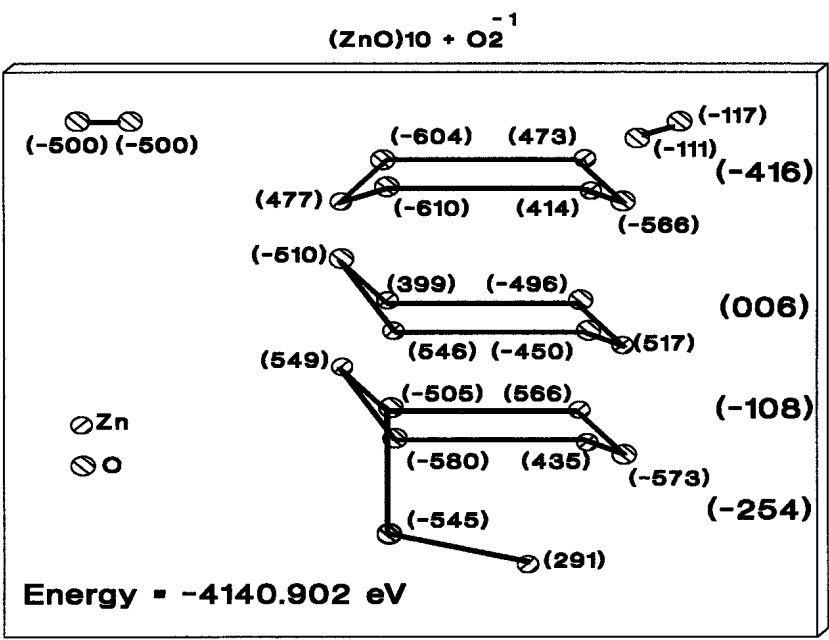

FIG. 5. Charge distribution of the $(\mathrm{ZnO})_{10} \cdot \mathrm{O}_{2}{ }^{-}$cluster showing that the adsorbed oxygen leads to a negative charge at the surface and positive charge in the bulk. The negative charge distribution of this system is higher than that of the $(\mathrm{ZnO})_{10} \cdot \mathrm{O}_{2}$ system. However, the bulk is lightly positive. The numbers in parentheses are the charge value in milielectron.

that a voltage barrier can be formed by the adsorption of oxygen molecules and atoms in the surface region of the $\mathrm{ZnO}$ cluster.

The charge distribution of the $\mathrm{ZnO}$ cluster shows that the oxygen species $\mathrm{O}_{2}, \mathrm{O}_{2}{ }^{-}$, and $\mathrm{O}^{-}$are responsible for the negative state at the $\mathrm{ZnO}$ surface (Figs. 4, 5, 6, and 8). Moreover, this negative surface can also be analyzed by the total energy calculation of the $(\mathrm{ZnO})_{10}$ cluster interacting with the different oxygen species.

To verify which oxygen species lead to major stability of the system, calculation for each species was considered. Considering the interaction of an oxygen

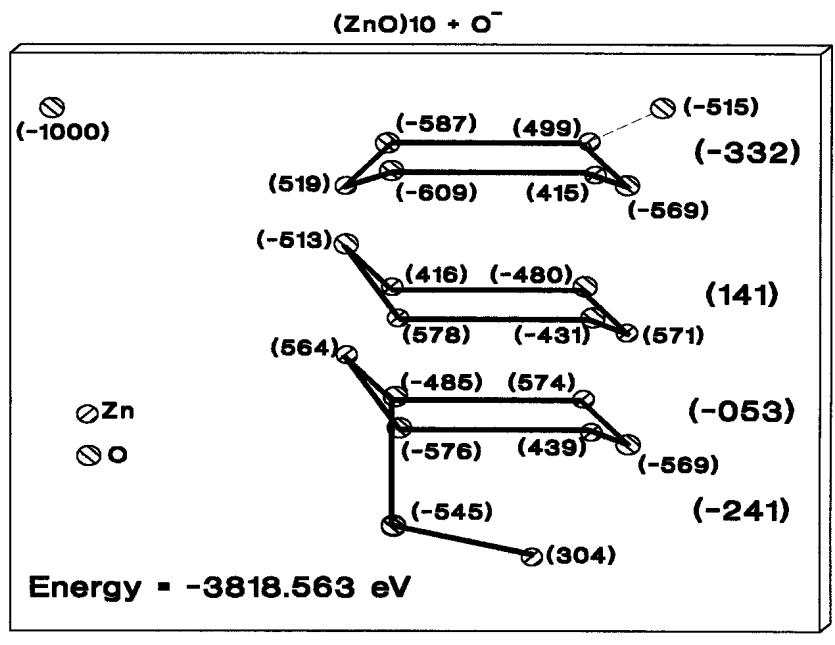

FIG. 6. Charge distribution of the $(\mathrm{ZnO}) 10 \cdot \mathrm{O}^{-}$cluster showing that the adsorbed oxygen leads to a negative charge at the surface and positive charge in the bulk. The numbers in parentheses are the charge value in milielectron.

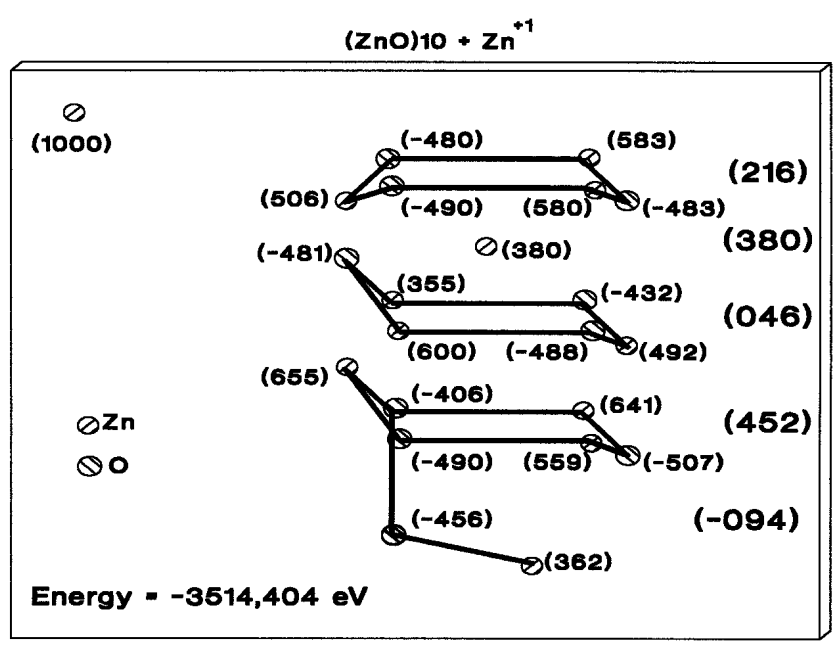

FIG. 7. Charge distribution of the $(\mathrm{ZnO})_{10} \cdot \mathrm{Zn}^{+1}$ cluster showing negative charge at the surface and positive charge in the bulk. The numbers in parentheses are the charge value in milielectron.

molecule on the $\mathrm{ZnO}$ surface, the energy value for this adsorption is

$$
(\mathrm{ZnO})_{10}+\mathrm{O}_{2} \rightarrow(\mathrm{ZnO})_{10} \cdot \mathrm{O}_{2} \quad \Delta E=0.78 \mathrm{eV}
$$

The experimental value obtained by Binesti ${ }^{21}$ for this adsorption is $0.8 \mathrm{eV}$. This indicates that the $\mathrm{ZnO}$ model considered is reasonable for this type of calculation. Results for interactions at different sites are similar, which leads to charge redistribution in the crystal and the increase of negative charge density at the surface (Figs. 4, 5, and 6).

The adsorption of $\mathrm{O}_{2}{ }^{-}$at the surface was also considered leading to:

$$
\begin{aligned}
(\mathrm{ZnO})_{10}+\mathrm{O}_{2}^{-} & +e^{\prime} \rightarrow(\mathrm{ZnO})_{10} \cdot 2 \mathrm{O}^{-} \\
\Delta E & =6.8 \mathrm{eV} .
\end{aligned}
$$




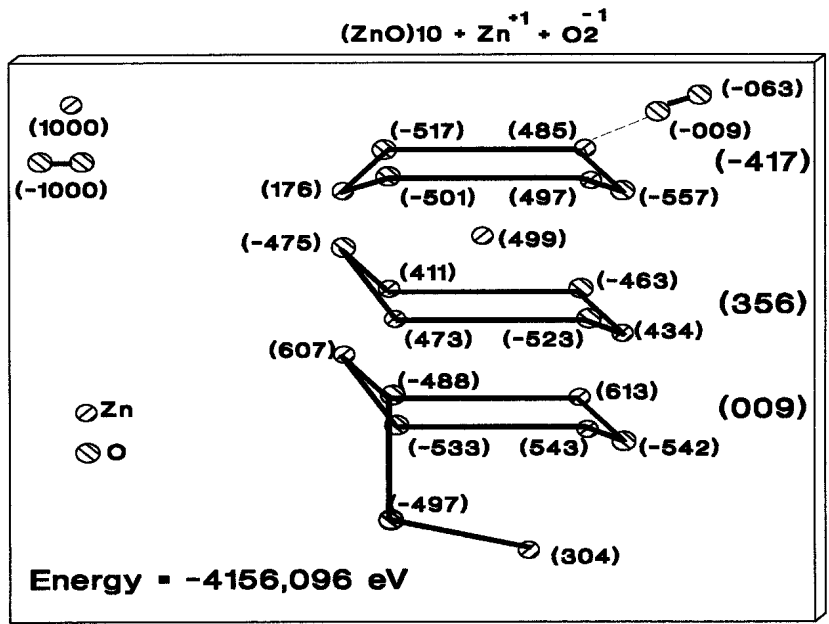

FIG. 8. Charge distribution of the $(\mathrm{ZnO})_{10} \cdot \mathrm{Zn}^{+1} \cdot \mathrm{O}_{2}{ }^{-}$cluster showing that the adsorbed oxygen leads to a negative charge at the surface and positive charge in the bulk. The numbers in parentheses are the charge value in milielectron.

In this case there is a break of an oxygen molecule bond and the system gains an extra electron to stabilize the reaction. This reaction needs a high energy to be completed and the probability that this species is at the $\mathrm{ZnO}$ surface is very low.

The model presented takes into account the nonstoichiometry of $\mathrm{ZnO}$ by placing an interstitial zinc as dominant defect. However, oxygen vacancies are also important and should be considered. Gupta and co-authors ${ }^{7,9-11}$ proposed that the degradation of $\mathrm{ZnO}$ varistors occurs by interstitial zinc diffusion from the depletion layer to the grain boundary. According to these authors cooling after sintering leads to freezing of interstitial zinc in the depletion layer. The application of an external electric field makes the migration of these ions to the interface possible. The presence of negative charge of the Schottky barrier at the surface leads to partial neutralization of the net charge. This effect is reversible after elimination of the electric field.

Considering the stoichiometric $\mathrm{ZnO}$ the charge density of the surface is negative. However, the presence of interstitial zinc ions can transform the surface charge density to a positive value (Figs. 7 and 8). Comparing Figs. 3 and 7 with 5 and 8 a significative increase of surface charge density is observed due to adsorbed $\mathrm{O}_{2}{ }^{-}$ and to the positive charge of the interstitial zinc ions. These results agree with the model where the oxygen ions and molecules are located at the surface creating a barrier for another neighbor cluster. Moreover, the electron moves more easily inside the cluster due to the positive charge generated by the interstitial zinc ion. These results are in agreement with the proposition of Gupta $^{7,9,10}$ in which the role of the positive charge is to neutralize the negative surface charge.
Takahashi et $a .^{22}$ suggested that at least part of the surface charge is due to oxygen ions. Considering that the degradation of $\mathrm{ZnO}$ varistors occurs mainly by the liberation of oxygen, it is reasonable to propose a reaction of the interstitial zinc ions $\left(\mathrm{Zn}^{+2}\right)$ and adsorbed oxygens $\left(\mathrm{O}^{-2}\right)$. However, this reaction is endothermic and involves $8 \mathrm{eV}$, which is not very likely for this system. Therefore, the adsorption of $\mathrm{O}_{2}, \mathrm{O}_{2}{ }^{-}$, and $\mathrm{O}^{-}$species was considered in a stoichiometric $(\mathrm{ZnO})_{10}$ model and in a nonstoichiometric $(\mathrm{ZnO})_{10} \mathrm{Zn}^{+}$. The results showed that to adsorb an oxygen molecule in the stoichiometry model, $0.78 \mathrm{eV}$ are necessary according to reaction (7). The system $(\mathrm{ZnO})_{10} \mathrm{O}_{2}$ can be reduced leading to:

$$
(\mathrm{ZnO})_{10} \cdot \mathrm{O}_{2}+e^{\prime} \rightarrow(\mathrm{ZnO})_{10} \cdot \mathrm{O}_{2}{ }^{-} \quad \Delta E=-1.7 \mathrm{eV} .
$$

Then for the oxygen adsorption and reduction the net reaction is:

$$
\begin{gathered}
(\mathrm{ZnO})_{10}+\mathrm{O}_{2}+e^{\prime} \rightarrow(\mathrm{ZnO})_{10} \cdot \mathrm{O}_{2}^{-} \\
\Delta E=-0.92 \mathrm{eV} .
\end{gathered}
$$

Then the reverse reaction (10) indicates the need of $0.92 \mathrm{eV}$ to liberate an oxygen from the $\mathrm{ZnO}$ cluster surface. This result is close to the experimental results obtained by Leite et al. ${ }^{23}$ during degradation of a $\mathrm{ZnO}$ varistor $(0.98 \mathrm{eV})$.

For the nonstoichiometric system the adsorption of oxygen is given by:

$$
\begin{gathered}
(\mathrm{ZnO})_{10} \cdot \mathrm{Zn}^{+}+\mathrm{O}_{2} \rightarrow(\mathrm{ZnO})_{10} \cdot \mathrm{Zn}^{+} \cdot \mathrm{O}_{2} \\
\Delta E=0.78 \mathrm{eV} \\
(\mathrm{ZnO})_{10} \cdot \mathrm{Zn}^{+} \mathrm{O}_{2}+e^{\prime} \rightarrow(\mathrm{ZnO})_{10} \cdot \mathrm{Zn}^{+} \cdot \mathrm{O}_{2}^{-} \\
\Delta E=-2.07 \mathrm{eV} .
\end{gathered}
$$

The net variation of reactions (11) and (12) is $\Delta E=-1.3 \mathrm{eV}$, indicating that the interstitial zinc ions are located near the surface. In this case the oxygen adsorption will be higher in this system compared to the stoichiometric system. As a consequence the degradation phenomena will be more difficult. There is also the possibility of the existence of double charged oxygen at the $\mathrm{ZnO}$ surface that is represented by the following reactions:

$$
(\mathrm{ZnO})_{10} \cdot \mathrm{O}_{2}+2 e^{\prime} \rightarrow(\mathrm{ZnO})_{10} \cdot \mathrm{O}_{2}^{-2} \quad \Delta E=0.7 \mathrm{eV},
$$

$$
(\mathrm{ZnO})_{10} \cdot \mathrm{O}_{2}^{-}+e^{\prime} \rightarrow(\mathrm{ZnO})_{10} \cdot \mathrm{O}_{2}^{-2} \quad \Delta E=1.6 \mathrm{eV} .
$$

By analyzing Eq. (14) it is observed that there is a very high energy barrier to reduce $\mathrm{O}_{2}{ }^{-}$to $\mathrm{O}_{2}^{-2}$. According to Shih-Chia Chang, ${ }^{24}$ this reaction should 
have a double ionization leading to $\mathrm{O}^{-}$adsorbed at the surface. The EPR data, however, agree with the theoretical calculation of Eq. (13).

The $\mathrm{O}_{2}{ }^{-}$adsorption at the $\mathrm{ZnO}$ surface is also possible and is represented by:

$$
\begin{gathered}
(\mathrm{ZnO})_{10}+\mathrm{O}_{2}{ }^{-} \rightarrow(\mathrm{ZnO})_{10} \cdot \mathrm{O}_{2}{ }^{-} \\
\Delta E=0.43 \mathrm{eV} \\
(\mathrm{ZnO})_{10} \cdot \mathrm{Zn}^{+}+\mathrm{O}_{2}{ }^{-} \rightarrow(\mathrm{ZnO})_{10} \cdot \mathrm{Zn}^{+} \cdot \mathrm{O}_{2}{ }^{-} \\
\Delta E=0.05 \mathrm{eV} .
\end{gathered}
$$

Moreover, by analyzing Table I the formation of oxygen and zinc vacancies in distinct sites can be inferred. The oxygen vacancies $\left(\mathrm{V}_{\mathrm{O}}{ }^{\bullet}\right.$ and $\left.\mathrm{V}_{\mathrm{O}}{ }^{\bullet}\right)$ are located at the surface cluster and the zinc vacancies $\left(\mathrm{V}_{\mathrm{Zn}}{ }^{\prime}\right.$ and $\left.\mathrm{V}_{\mathrm{Zn}}{ }^{\prime \prime}\right)$ inside the cluster.

Considering that the energy calculated for $(\mathrm{ZnO})_{10}$ cluster is $-3499.608 \mathrm{eV}$, for $(\mathrm{ZnO})_{9} \mathrm{Zn} \cdot \mathrm{V}_{\mathrm{O}} \cdot \mathrm{O}^{-}$ is $-3499.632 \mathrm{eV}$, and for $(\mathrm{ZnO})_{9} \mathrm{O} \cdot \mathrm{V}_{\mathrm{Zn}}{ }^{\prime} \cdot \mathrm{Zn}{ }^{\bullet}$ is $-3499.449 \mathrm{eV}$, we may conclude that the creation of oxygen vacancies is a spontaneous characteristic of the $n$-type semiconducting behavior of $\mathrm{ZnO}$.

According to Eda et al. ${ }^{25}$ and Gupta and Carlson, ${ }^{26}$ the most probable mechanism for potential barrier stabilization is interstitial diffusion of zinc through the $\mathrm{ZnO}$ crystal to the grain boundary. The theoretical results confirm this premise for interstitial zinc ions $\left(\mathrm{Zn}_{i}{ }^{\bullet}\right.$ and

TABLE I. Stability of zinc and oxygen vacancies in the $(s)$ surface of $\mathrm{ZnO}$ grain and (i) inside the $\mathrm{ZnO}$ grain.

\begin{tabular}{lcc}
\hline \hline $\mathrm{ZnO}$ clusters & $-E(\mathrm{eV})$ & Energy gap $(\mathrm{eV})$ \\
\hline$(\mathrm{ZnO})_{9} \mathrm{O} \cdot \mathrm{V}_{\mathrm{Zn}}{ }^{\prime \prime}(s)$ & 3464.620 & 4.8 \\
$(\mathrm{ZnO})_{9} \mathrm{O} \cdot \mathrm{V}_{\mathrm{Zn}}{ }^{\prime \prime}(i)$ & 3468.337 & 6.6 \\
$(\mathrm{ZnO})_{9} \mathrm{O} \cdot \mathrm{V}_{\mathrm{Zn}^{\prime}}{ }^{\prime}(s)$ & 3466.443 & 2.3 \\
$(\mathrm{ZnO})_{9} \mathrm{O} \cdot \mathrm{V}_{\mathrm{Zn}}{ }^{\prime}(i)$ & 3469.235 & 2.0 \\
$(\mathrm{ZnO})_{9} \mathrm{Zn} \cdot \mathrm{V}_{\mathrm{O}} \cdot \bullet(s)$ & 3159.558 & 3.2 \\
$(\mathrm{ZnO})_{9} \mathrm{Zn} \cdot \mathrm{V}_{\mathrm{O}} \cdot \cdot(i)$ & 3158.275 & 5.5 \\
$(\mathrm{ZnO})_{9} \mathrm{Zn} \cdot \mathrm{V}_{\mathrm{O}} \cdot(s)$ & 3170.989 & 1.7 \\
$(\mathrm{ZnO})_{9} \mathrm{Zn} \cdot \mathrm{V}_{\mathrm{O}} \cdot(i)$ & 3169.505 & 3.1 \\
$(\mathrm{ZnO})_{9} \cdot \mathrm{V}_{\mathrm{O}} \cdot(i) \cdot \mathrm{V}_{\mathrm{Zn}}{ }^{\prime}(s)$ & 3139.549 & 4.1 \\
$(\mathrm{ZnO})_{9} \cdot \mathrm{V}_{\mathrm{O}} \cdot(i) \cdot \mathrm{V}_{\mathrm{Zn}}{ }^{\prime}(i)$ & 3142.607 & 2.8 \\
$(\mathrm{ZnO})_{10} \mathrm{Zn}_{i} \cdot \bullet(s)$ & 3503.859 & 2.6 \\
$(\mathrm{ZnO})_{10} \mathrm{Zn}_{i} \cdot \bullet(i)$ & 3491.927 & 4.5 \\
$(\mathrm{ZnO})_{10} \mathrm{Zn}_{i} \cdot(s)$ & 3514.404 & 3.7 \\
$(\mathrm{ZnO})_{10} \mathrm{Zn}_{i} \cdot(i)$ & 3504.415 & 3.1 \\
\hline \hline
\end{tabular}

Mean value of energy gap 3.6.
$\left.\mathrm{Zn}_{i}{ }^{\bullet}\right)$ as seen in Table I. These interstitial zinc ions create a positive charge density in the depletion layer (Figs. 7 and 8). This layer would be associated to oxygen vacancies $\left(\mathrm{V}_{\mathrm{O}}{ }^{\bullet}\right.$ and $\left.\mathrm{V}_{\mathrm{O}}{ }^{\bullet}\right)$ that migrate to the surface. This fact would facilitate the oxygen adsorption at the crystal surface. However, the results of Table I show that zinc vacancies $\left(\mathrm{V}_{\mathrm{Zn}}{ }^{\prime}\right.$ and $\left.\mathrm{V}_{\mathrm{Zn}}{ }^{\prime \prime}\right)$ are located inside the $\mathrm{ZnO}$ cluster and would not directly participate in the superficial charge formation.

Considering that the nonohmic properties of $\mathrm{ZnO}$ varistors are due to the Schottky type potential barriers, the grain boundary negative charges are compensated by positive charges located at the depletion layer of $\mathrm{ZnO}$ grains. In this way the grain boundary atomic defect model is proposed to represent the $\mathrm{ZnO}$ varistor, where negative superficial charge states are $\mathrm{O}_{2}, \mathrm{O}^{-}$, and $\mathrm{O}_{2}{ }^{-}$ and positive states are $\mathrm{V}_{\mathrm{O}}{ }^{\bullet}, \mathrm{V}_{\mathrm{O}}{ }^{\bullet}, \mathrm{Zn}_{i}{ }^{\bullet}$ and dopants $\mathrm{V}_{\mathrm{M}}{ }^{\bullet}, \mathrm{V}_{\mathrm{M}}{ }^{\bullet}$ (Fig. 9).

This model is basically similar to that proposed by Gupta $^{25}$ with the addition of oxygen ions and molecular oxygen adsorbed at the grain boundary. These defects together with interstitial zinc ions $\left(\mathrm{Zn}_{i}{ }^{{ }^{\circ}}\right.$ and $\left.\mathrm{Zn}_{i}{ }^{\bullet}\right)$ and oxygen vacancies $\left(\mathrm{V}_{\mathrm{O}}{ }^{\bullet}\right.$ and $\left.\mathrm{V}_{\mathrm{O}}{ }^{\bullet}\right)$ are responsible for the $\mathrm{ZnO}$ grain boundary atomic defects.

The above defects form the depletion layer at the grain boundary region of zinc oxide, increasing the nonohmic behavior of this oxide.

Previous theoretical cluster calculations of the zinc oxide surfaces and adsorption process include the discrete variational (DV) $x$ - $\alpha$ model, ${ }^{27,28}$ semiempirical $(\mathrm{INDO} / \mathrm{S}),{ }^{29}$ and extend Hückel methods ${ }^{30}$ of the energy gap HOMO-LUMO. The theoretical calculations of

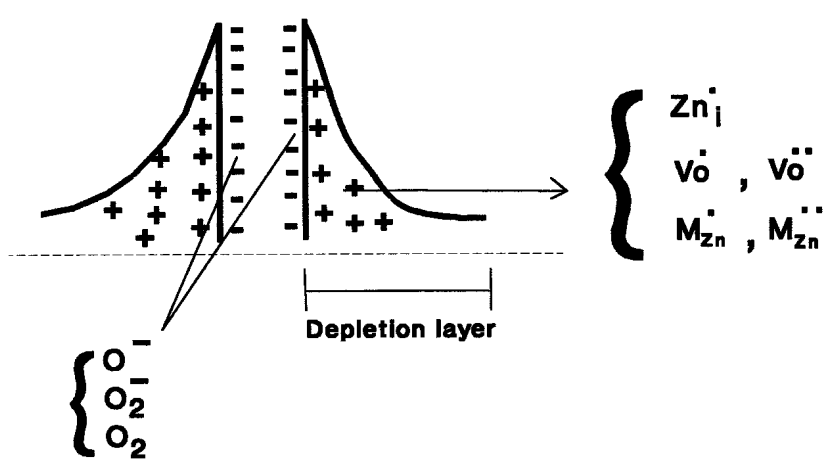

FIG. 9. Atomic defect model for $\mathrm{ZnO}$ grain boundary.

TABLE II. Theoretical and experimental results from the literature for the HOMO-LUMO gap of different ZnO clusters.

\begin{tabular}{lllllll}
\hline \hline & Exp. & DV-Xa & DV-Xa & INDO/S & EHT & MNDO (this work) \\
\hline Gap (eV) & 3.3 & 3.2 & 1.2 & 4.4 & 3.0 & 3.6 \\
Cluster & $\cdots$ & $\mathrm{Zn}_{7} \mathrm{O}_{11}$ & $\mathrm{Zn}_{3} \mathrm{O}_{10}$ & $\mathrm{Zn}_{13} \mathrm{O}_{13}$ & $2 \mathrm{Zn}_{9} \mathrm{O}_{9}$ & $\mathrm{Zn}_{10} \mathrm{O}_{10} \cdot x$ \\
Ref. & 31 & 27 & 28 & 29 & 30 & \\
\hline \hline
\end{tabular}

$x=\mathrm{V}_{\mathrm{Zn}^{\prime}}{ }^{\prime \prime}, \mathrm{V}_{\mathrm{Zn}^{\prime}}, \mathrm{V}_{\mathrm{O}}{ }^{\bullet}, \mathrm{V}_{\mathrm{O}} \cdot \mathrm{Zn}_{i}{ }^{\bullet}$, and $\mathrm{Zn}_{i} \cdot$ 
Refs. 27 and 30 in Table II agree with the experimental value of the crystal bulk $(3.3 \mathrm{eV}){ }^{31}$

In the present work the mean value for the energy gap calculated for the $14 \mathrm{ZnO}$ clusters is $3.6 \mathrm{eV}$ in agreement with experimental data. This result shows that to simulate the energy gap of a crystalline solid not only the defect concentration (vacancies and interstitial ions) should be considered, but also its position (surface or bulk).

\section{CONCLUSIONS}

The theoretical calculations lead to the following conclusions:

(1) The $\mathrm{ZnO}$ proposed model represents very well the semiconducting properties of this oxide in both surface and bulk.

(2) The interstitial $\mathrm{Zn}^{+}$species near the grain boundary decrease the negative surface state due to redistribution of charge and favor the adsorption of oxygen.

(3) The adsorption of $\mathrm{O}^{-}, \mathrm{O}_{2}{ }^{-}$, and $\mathrm{O}_{2}$ at the $\mathrm{ZnO}$ surface stabilizes the $\mathrm{ZnO}$ system, increasing the varistor properties. The desorption of these species leads to $\mathrm{ZnO}$ varistor degradation.

\section{REFERENCES}

1. G.E. Pike and C.H. Seager, J. Appl. Phys. 50, 3414 (1979).

2. M. Matsuoka, Jpn. J. Appl. Phys. 10, 73 (1971).

3. W.D. Kingery and H.K. Bowen, Introduction of Ceramics, 2nd ed. (John Wiley \& Sons, New York, 1975).

4. G. D. Mahan, J. Appl. Phys. 54, 3825 (1983).

5. V. Schwing and B. Hoffmann, J. Appl. Phys. 57, 5372 (1985).

6. K. Sato and Y. Takada, Advances in Ceramics, edited by F. M. Yan and H. H. Heuer (1983), Vol. 7, p. 22.
7. T. K. Gupta and W. G. Carlson, J. Mater. Sci. 20, 3487 (1985).

8. K. Sato and Y. Takada, J. Appl. Phys. 53, 8819 (1982).

9. T. K. Gupta and W. G. Carlson, J. Appl. Phys. 52, 4104 (1981).

10. T. K. Gupta and W. G. Carlson, Advances in Ceramics, edited by F. M. Yan and H. H. Heuer (1983), p. 30.

11. T. K. Gupta and W. G. Carlson, J. Appl. Phys. 53, 7401 (1982).

12. M. J. S. Dewar and W. J. Thiel, Am. Ceram. Soc. 9, 4899 (1977).

13. J. J. P. Stewart, Quantum Chem. Prog. Exch. Bull., 343 (1983).

14. M. J.S. Dewar and K. M. Merz, Jr., Organometallics 5, 1494 (1986).

15. M.J.S. Dewar and K.M. Merz, Jr., Organometallics 7, 552 (1988).

16. J. J. P. Stewart, J. Comp. Chem. 12, 320 (1991).

17. T. Oshiro, C. K. Lutrus, D. E. Hagen, S. Beck, and S. H. S. Salk, Solid State Commun. 87, 801 (1993).

18. J. B. L. Martins, E. Longo, and J. Andres, Int. J. Quantum Chem. 27, 643 (1993)

19. J. B. L. Martins, J. Andres, E. Longo, and C. A. Taft, Int. J. Quantum Chem. (1995) (in press).

20. S. Fujitsu, K. Koumoto, and H. Yanagida, Solid State Ionics 32/33, 482 (1989).

21. D. Binesti, Ph.D. Thesis, University of Bordeaux I, France (1985).

22. K. Takahashi, U. Miyoshi, K. Maeda, and O. Namazaki, Grain Boundaries in Semiconductors (Elsevier, New York, 1982), p. 39.

23. E. R. Leite, J. A. Varela, and E. Longo, J. Mater. Sci. 27, 5325 (1992).

24. Shih-Chi-Chang, J. Vac. Sci. Technol. 17, 242 (1980).

25. K. Eda, J. Appl. Phys. 49, 2964 (1978).

26. T. K. Gupta and W. G. Carlson, J. Appl. Phys. 53, 7401 (1982).

27. R. Kuwabara, H. Adachi, and T. Morimoto, Surf. Sci. 193, 271 (1988).

28. R. Sekine, H. Adachi, and T. Morimoto, Surf. Sci. 208, 177 (1989).

29. R. C. Baetzold, J. Phys. Chem. 89, 4150 (1985).

30. J. A. Rodriguez and C. T. Campbell, Langmuir 4, 1006 (1988); J. A. Rodriguez and C.T. Campbell, J. Phys. Chem. 91, 6648 (1987).

31. L. Ley, R. A. Pollack, F. R. McFeely, S. P. Kowalczk, and D. A. Shirley, Phys. Rev. B 9, 600 (1974). 